\title{
A gênese e o desenvolvimento da empatia: fatores formativos implicados
}

\author{
Genesis and development of empathy: formative factors involved
}

Gisele Schmidt Moitoso ${ }^{a}$, Cledes Antonio Casagrande ${ }^{b}$

\section{Editores}

Maria Inês Côrte Vitoria PUCRS, RS, Brasil Pricila Kohls dos Santos PUCRS, RS, Brasil

\section{Equipe Editorial}

Rosa Maria Rigo

PUCRS, RS, Brasil

\section{ISSN 2179-8435}

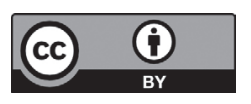

Este artigo está licenciado sob forma de uma licença Creative Commons Atribuição 4.0 Internacional, que permite uso irrestrito, distribuiçăo e reprodução
em qualquer meio, desde que a publicaçăo original seja corretamente citada http://creativecommons.org/licenses/by/4.0/deed.pt BR

\section{RESUMO}

Este artigo tem por objetivo apresentar resultados parciais de uma pesquisa de natureza qualitativa, em andamento, sobre a gênese da empatia e sobre o modo como ocorre o seu desenvolvimento na infância. A metodologia utilizada compõe-se de revisão bibliográfica e análise hermenêutica. Os dados da pesquisa permitiram compreender a empatia como a capacidade natural que um indivíduo tem de ser tocado pelo estado emocional alheio. Ademais, do estudo emergiram outros três aspectos referentes à empatia. $\mathrm{O}$ primeiro, oriundo de uma aproximação histórico-conceitual, permite entender a empatia como uma competência já conhecida, primariamente denominada 'simpatia', e relacionada à experiência estética do ser humano. O segundo relaciona a gênese da empatia a duas vertentes: uma vinculada aos estudos com crianças, que detectou a presença da empatia em bebês, e outra que compreende a empatia em um contexto evolucionista, como uma característica compartilhada com outros animais mamíferos. O terceiro aspecto aponta a possibilidade de formar a empatia e outros elementos da moralidade humana desde o nascimento. Dado que a empatia consiste em uma competência fundamental à convivência humana, presente desde o nascimento, é preciso e possível promovê-la pela via da formação familiar e escolar.

Palavras-chave: Empatia; Infância; Desenvolvimento humano; Formação.

\section{ABSTRACT}

This article aims to present partial results of a qualitative and ongoing research on the genesis of empathy and how it develops in childhood. The methodology used is the bibliographical review and the hermeneutical analysis. Research data allowed us to understand empathy as the natural ability of an individual to be touched

\footnotetext{
a Bolsista de Iniciação Científica do Programa de Pós-Graduação em Educação e acadêmica do Curso de Psicologia da Universidade La Salle (Canoas/RS).

b Doutor em Educação. Docente e pesquisador do PPG em Educação - Mestrado e Doutorado - da Universidade La Salle (Canoas/RS).
} 
by the emotional state of others. In addition, three other aspects of empathy emerged from the study. The first, derived from a historical-conceptual approach, allows us to understand empathy as an already known competence, primarily called 'sympathy', and related to the aesthetic experience of the human being. The second relates the genesis of empathy to two aspects: one related to studies with children, which detected the presence of empathy in infants, and another that comprises empathy in an evolutionary context, as a feature shared with other mammalian animals. The third aspect points to the possibility of forming empathy and other elements of human morality since birth. As empathy consists of a fundamental competence for human coexistence, present since birth, it is necessary and possible to promote it through family and school formation.

Keywords: Empathy; Childhood; Human development; Formation.

\section{Introdução}

Esents ste artigo, atrelado ao projeto de pesquisa Solidariedade, experiência e educação: o problema da formação em contextos plurais e de múltiplas linguagens, de um Programa de Pós-Graduação em Educação, pretende apresentar resultados parciais oriundos da investigação sobre a gênese da empatia e como ocorre o seu desenvolvimento na infância, atentando especialmente para o papel formativo da família. A questão que aqui se quer responder é: como a literatura disponível descreve a gênese e o desenvolvimento da empatia, especialmente na infância, e qual o papel formativo da família no desenvolvimento dessa competência humana?

A pesquisa que dá origem a este texto é de natureza qualitativa, do tipo revisão bibliográfica, com análise hermenêutica dos dados. Uma pesquisa de natureza qualitativa é indicada para nortear a investigação de fenômenos sociais, com interesse de perscrutar aquilo que não é manifesto no universo das ações e das relações humanas, através da compreensão e da interpretação dos sentidos e dos significados intrínsecos dos objetos problematizados. Além disso, uma pesquisa qualitativa consiste em

[...] um conjunto de práticas materiais e interpretativas que dão visibilidade ao mundo. Essas práticas transformam o mundo em uma série de representações [...]. Nesse nível, a pesquisa qualitativa envolve uma abordagem naturalista, interpretativa, para mundo, o que significa que seus pesquisadores estudam as coisas em seus cenários naturais, tentando entender, ou interpretar os fenômenos em termos de significados que as pessoas a eles conferem (DENZIN e LINCOLN, 2006, p. 17). 
Essa revisão de literatura sobre o tema ocorreu a partir da consulta em livros, artigos científicos e dissertações, como preconiza Gil (2014). A análise dos dados seguiu a perspectiva hermenêutica, especialmente a proposta por Gadamer (2005), com esforço para contextualizar, compreender, interpretar e aplicar os principais conceitos e categorias advindos da pesquisa. Nesse sentido, esse autor afirma:

Em princípio, quem quer compreender um texto deve estar disposto a deixar que este lhe diga alguma coisa. Por isso, uma consciência formada hermeneuticamente deve, desde o princípio, mostrar-se receptiva à alteridade do texto. Mas essa receptividade não pressupõe nem uma 'neutralidade' com relação à coisa nem tampouco um anulamento de si mesma; implica antes uma destacada apropriação das opiniões prévias e preconceitos pessoais. O que importa é dar-se conta dos próprios pressupostos, a fim de que o próprio texto possa apresentar-se em sua alteridade, podendo assim confrontar sua verdade com as opiniões prévias pessoais $(2005$, p. 358$)$.

Essa postura metodológica permite, de acordo com Stein (1996, p. 55),

[ [...] aproximar-nos de um texto com a pressuposição de que existe uma história dos conceitos que nos dá possibilidade de converter o texto num texto atual. Isto quer dizer, reconstruir através de processos interpretativos o texto e dar-lhe uma forma contemporânea.

Como compreensão preliminar, pode-se dizer que a empatia consiste na capacidade que um indivíduo tem de se colocar no lugar do outro, de ser tocado pelo estado emocional de outro indivíduo (DE WAAL, 2007), de compreender sentimentos e compartilhar da perspectiva do outro, reagindo de modo a expressar tal compreensão (RIBEIRO, 2011). Ademais, trata-se de uma característica, competência ou capacidade presente em seres humanos desde o início da existência, quando a criança, nos primeiros meses de vida, demonstra a habilidade para expressar sinais emocionais que são importantes à própria sobrevivência e também para responder aos sinais emitidos por outros (MONTAGNER, 1996).

A empatia também está presente nas relações interpessoais, possibilitando o convívio e a organização social; possui papel fundamental no desenvolvimento moral e de atitudes altruísticas (STUEBER, 2016). Quando considerada sob o prisma do desenvolvimento psicológico e moral, autores reconhecem que seu desenvolvimento inicia-se no contexto familiar, a partir das experiências de socialização que são propiciadas ao infante pelas pessoas mais próximas (GARCIA, 2001). Há autores, como Frans De Waal (2010), que consideram a empatia desde uma perspectiva da 
evolução natural dos seres humanos, sendo compartilhada e também estando presente nos comportamentos de outros mamíferos, como bonobos e chimpanzés.

Ademais, existem outras vertentes históricas acerca da evolução da moralidade que tendem a discordar da possibilidade de que esta possa ser objeto de ensino e aprendizagem ${ }^{1}$. Essa perspectiva antepõe-se a outra que entende a moral e, por consequência, a competência para a empatia e solidariedade. Como exemplo, as aprendizagens advindas do processo de socialização, conformando como que uma segunda natureza do ser humano. Não é intenção, neste artigo, defender uma posição ou outra. Pretende-se somente, como já foi expresso, situar o discurso teórico, hoje corrente, relativo à gênese da empatia e entender como ocorre o seu desenvolvimento na infância. Isso permite, posteriormente, assumir a possibilidade de que a empatia possa ser desenvolvida na infância, mediante vivências e experiências familiares e grupais.

A partir dessa primeira aproximação ao tema, no primeiro tópico do texto, apresentam-se alguns dados históricoconceituais acerca da evolução e da compreensão do conceito de empatia na história do pensamento ocidental. Posteriormente, no segundo tópico, faz-se uma reflexão sobre a gênese e sobre a presença da empatia em crianças; além disso, tematiza-se a empatia desde uma perspectiva evolucionista e naturalista, como uma característica específica dos animais mamíferos. Finalmente, aborda-se a empatia sob o prisma formativo e do seu possível desenvolvimento no seio familiar.

\section{Empatia: uma primeira aproximação histórico-conceitual}

Inicialmente, esboça-se uma primeira aproximação histórico-conceitual ao conceito de empatia. Nessa tarefa, segue-se a recomendação metodológica proposta por Gadamer no que concerne à necessidade de se conhecer os conceitos a partir dos quais se opera. Nesse sentido, Gadamer (2007, p. 11) afirma:

Venho seguindo há muito tempo o princípio metodológico de não empreender nada sem uma prestação de contas histórico-conceitual. É preciso prestar contas de nossa pré-conceitualidade para o nosso filosofar, na medida em que procuramos esclarecer a implicação dos termos conceituais com os quais a filosofia lida.

\footnotetext{
1 Por exemplo, Aristóteles (2007), em Ética a Nicômaco, afirma que a prudência (phrónesis), ou sabedoria prática de bem julgar, não pode ser ensinada, diferentemente da arte, do criar (poiésis) e da teoria. Entretanto, como se trata de uma ação reflexiva, uma práxis, o meio para adquiri-la é a experiência; ou seja, quanto mais experiente o sujeito for, maior possibilidade ele terá de agir com prudência e sabedoria.
} 
O conceito de empatia possuiu sua história ligada à filosofia e à psicologia, destacando-se especialmente a partir do final do século XIX e do início do século XX. Recentemente, tal conceito adquiriu relevância para se entender a capacidade de ação do ser humano em diferentes contextos, bem como para compreender a constituição moral e social da personalidade (STUEBER, 2016). Theodor Lipps foi o primeiro autor a relacionar o conceito de empatia com a experiência estética do ser humano. Ao referir-se a esse autor, Stueber (2006, p. 07) afirma que Lipps concebeu a "empatia não apenas como um importante conceito estético, mas como uma categoria sociológica e psicológica básica", visto que esta desempenha um papel importante não apenas na percepção dos objetos, mas também se constitui numa referência básica para que se reconheça a própria condição de criatura consciente.

O psicólogo canadense Paul Bloom (2014) enfatiza que o impulso da empatia, em decorrência de ser poderoso, é irresistível. Sua denominação surgiu somente em 1909, quando a palavra alemã Einfühlung, que significa 'sentir-se em', foi traduzida ao inglês como empathy. Historicamente, além de Theodor Lipps, outro autor foi importante para a afirmação do conceito de empatia: Adam Smith. Bloom (2014), ao referir-se a Smith, afirma que o pai da economia moderna, apesar de não ter utilizado o termo 'empatia', definiu-o muito eficientemente, como sendo a capacidade de imaginar-se ou de colocar-se no lugar do outro.

A partir da leitura da obra de Adam Smith, intitulada A teoria dos sentimentos morais, publicada originalmente em 1759, verifica-se que o autor faz uso do termo 'simpatia' para descrever o sentimento que, nos tempos atuais, e no contexto do presente estudo, corresponde ao conceito de empatia, porquanto descreve o movimento interno que um indivíduo realiza de sentir aquilo que o outro sente. Nesse sentido, Smith afirma: "Como não temos experiência imediata do que os outros homens sentem, somente podemos formar uma ideia da maneira como são afetados se imaginarmos o que nós mesmos sentiríamos numa situação semelhante" (2015, p. 5-6).

Smith assevera que nossos sentidos não permitem propriamente sentir o que o outro sente, conhecer a experiência vivenciada pelo corpo e pela mente alheia. Afirma que é pela imaginação que se alcança tal percepção:

[...] e apenas pela imaginação nos é possível conceber em parte quais as suas sensações. Tampouco essa faculdade nos pode ajudar senão representando para nós as próprias sensações se nos encontrássemos em seu lugar. Por intermédio da imaginação podemos nos colocar no lugar do outro, concebemo-nos sofrendo os mesmos tormentos [...]. Assim, incorporadas em nós mesmos, adotadas e tornadas nossas, suas agonias começam finalmente a nos afetar, e então tememos, e sentimos calafrios, apenas à imagem do que ele está sentindo (SMITH, 2015, p. 6, grifo inerente a este artigo).

O autor usa como exemplos situações de tortura e sofrimento, mas enfatiza que é possível esclarecer a questão de muitos outros modos, explorando variados eventos e sentimentos, e que ainda assim é 
possível perceber-se sentindo (ou imaginando sentir) o que o outro sente. Nesse ponto, Smith usa o termo 'solidariedade'; porém entende-se que o significado do conceito do que ele refere remete ao que hoje se traduz por empatia:

Essas circunstâncias que produzem tristeza ou dor não são as únicas que provocam nossa solidariedade. Seja qual for a paixão que proceda de um objeto qualquer na pessoa primeiramente atingida, uma emoção análoga brota no peito de todo espectador atento ao pensar na situação das outras. Nossa alegria pela salvação dos heróis que nos interessam nas tragédias ou romances é tão sincera quanto nossa dor pela sua aflição, e nossa solidariedade para com seu infortúnio não é mais real do que para com sua felicidade (SMITH, 2015, p. 7, grifo nosso).

Adam Smith não explora a gênese do conceito que ora corresponde à empatia. Ou seja, ele não realiza um estudo investigativo acerca de como essa faculdade se origina na espécie humana. Ainda assim, devido à impactante contribuição de seu pensamento, as reflexões que tece a respeito dos sentimentos morais - como denomina -, entre eles o arcabouço da empatia, são de extrema relevância no estudo dessa capacidade no horizonte das ciências humanas e sociais.

Atualmente, o conceito de empatia abarca várias conotações, entre as quais destacam-se: colocar-se no lugar do outro; sentir como sente outra pessoa; ser tocado pelo que sente o outro indivíduo; conectar-se emocionalmente a outro ser humano. Todas as acepções apontam para uma mesma direção: a alteridade, o outro.

O Dicionário de Psicologia de Stratton e Hayes define empatia como

[...] um sentimento de compreensão e unidade emocional com alguém, de modo que uma emoção sentida por uma pessoa é vivenciada em alguma medida por outra que se empatiza com ela. A empatia é algumas vezes empregada na indicação do grau de capacidade de um indivíduo para ser empático com os outros. Ser empático é considerado uma condição importante para os psicoterapeutas (2003, p. 81).

Outro dicionário tomado como referência pela Psicologia, o Dicionário de Psicologia da APA (American Psychological Association), traz a seguinte acepção para empatia:

[...] compreender uma pessoa a partir do quadro de referência dela e não do próprio, de modo a experimentar de modo vicário os sentimentos, [as] percepções e [os] pensamentos dela. A empatia não envolve por si mesma a motivação para ajudar, embora possa se transformar em consideração pelo outro ou sofrimento pessoal, o que pode resultar em ação. Em psicoterapia, a empatia do terapeuta pelo cliente pode ser um caminho para compreender as cognições, [os] afetos ou [os] comportamentos do cliente (2010, p. 335). 
De acordo com Justo, Carvalho e Kristensen (2014), no rol dos comportamentos humanos, existem pelo menos duas diferentes e possíveis reações empáticas, quais sejam:

a) propensão para agir pró-socialmente, quando o indivíduo se utiliza da capacidade de compreensão para auxiliar o outro a aliviar seu desconforto;

b) sofrimento pessoal que faz com que o indivíduo empenhe estratégias para aliviar o próprio sofrimento quando presencia o desconforto do outro.

Como se tem visto, a empatia representa uma competência essencial para a evolução da espécie humana ao longo do tempo, pois é preciso que cada indivíduo consiga, em alguma medida, colocar-se no lugar de seu semelhante. Se um indivíduo for empático, terá a capacidade de perceber ou entender o que o outro sente, deseja e necessita. Assim, poderá respeitar o espaço alheio, favorecendo a convivência social e a manutenção da harmonia do grupo.

Seguindo a compreensão da empatia enquanto capacidade de colocar-se no lugar do outro, um comportamento pró-social por natureza, na sequência apresentam-se algumas teorias referentes à gênese dessa faculdade, buscando conhecer como esta surge na espécie humana. Em seguida, reflete-se sobre como ocorre o desenvolvimento da empatia durante a infância, atentando para o papel da família em tal processo.

\section{Gênese da empatia e natureza humana}

Na revisão de literatura realizada, encontram-se vários estudos relativos à empatia, o que demonstra que esse tema tem ganhado destaque nas pesquisas na área das ciências humanas. Destacam-se aqui duas vertentes sobre a gênese da empatia, as quais, embora distintas, confluem quando entendidas sob uma perspectiva biológica e evolutiva: a primeira está relacionada aos estudos com crianças, especificamente com o desenvolvimento ou com a presença da empatia em bebês [i]; a segunda compreende a empatia em um contexto naturalista e evolucionista, como uma característica específica dos animais mamíferos [ii].

\section{[i]}

Há evidências de que a empatia está presente nas pessoas desde o início da vida, quando o bebê já tem capacidade para expressar sinais emocionais importantes à sobrevivência e também para responder aos sinais emitidos por outras pessoas (MONTAGNER, 1996). O próprio choro de um bebê recém-nascido, em resposta ao choro de outro bebê, pode ser entendido como um indicador da presença da empatia.

Nesse sentido, a pesquisa de Bussab, Pedrosa e Carvalho (2007), no intuito de argumentar acerca da ontogênese da empatia, relata um episódio de cuidado entre dois bebês. As pesquisadoras iniciam seu artigo descrevendo a 
situação ocorrida no berçário de um orfanato e registrada por uma câmera. Um menino de nove meses ouve outro menino, com treze meses, chorando. Engatinha até ele e, ao encontrá-lo, toca-lhe desajeitadamente a cabeça e as costas, como num gesto de carinho. Cessado o choro, ambos se olham e, como estão próximos a um berço, começam a brincar em torno do móvel, esboçando sorrisos. As autoras entendem que o gesto protagonizado pelo bebê de nove meses representa um ato de empatia, porquanto ele parece ter percebido o desconforto do outro menino, tentando de alguma maneira minimizá-lo, ainda que não o tenha feito de modo consciente e intencional.

Lordelo e Carvalho (1989) afirmam que as crianças, desde muito novas, mimetizam comportamentos de cuidado e proteção de adultos no que se refere a crianças menores que elas. Isso inclui, por exemplo, modificar a postura para nivelar-se com elas e modular a voz para dirigir-se a elas, atitudes que revelam uma intenção, ainda que não tão consciente no infante, de fazer com que a criança menor se sinta acolhida em sua relativa fragilidade diante da maior.

Bussab, Pedrosa e Carvalho (2007, p. 107) concordam com essa ideia ao afirmarem que

as demonstrações das capacidades precoces de recém-nascidos para o engajamento interpessoal apontam uma pré-adaptação a um ambiente de envolvimento interpessoal consistente [...]. A natureza humana parece ter ajustado o indivíduo para se desenvolver em função da rede social e afetiva na qual ele está imerso.

Celso Gutfreind (2006) afirma, com base no que grande parte da literatura acerca do desenvolvimento humano sustenta e naquilo que a observação cotidiana permite-lhe perceber, que a espécie humana nasce frágil e muito voltada para si. Embora não duvide disso, o autor alerta para o fato de que a própria ciência nota, cada vez mais, por meio de estudos com bebês, que é muito precoce o interesse pelo outro.

Nascemos com vontade de encontrar, ensinou-nos Bowlby. E se fomos devidamente olhados, como mostraram Lacan e Winnicott, a base será sólida. E por detrás dessa base, entre comida e roupa, avultou a empatia. Ou a solidariedade. Bebês são rápidos para a saúde e a doença. Para o egoísmo e o altruísmo. Para os sentidos. E, antes de completar um ano de vida, já podem se mostrar solidários. Às vezes fico pensando o quanto os umbigos excessivos ou sem muita abstração devem a processos malogrados lá no início, quando ainda se cuidava concretamente do coto umbilical do bebê (GUTFREIND, 2006, p. 22).

O já citado Bloom (2014) igualmente entende que há algo de muito primitivo no comportamento moral dos bebês. Em sua obra intitulada $\mathrm{O}$ que nos faz bons ou maus, compartilha experimentos que já revelaram que o ser humano tem um senso moral que o autoriza a julgar as outras pessoas e que orienta a sua compaixão e a sua 
reprovação: "Somos naturalmente gentis com os outros, pelo menos em alguns momentos" (2014, p. 18). Devido à imaturidade cerebral do bebê, o autor afirma não defender que isso está presente desde o nascimento. Ainda diz: “[...] O que estou propondo, entretanto, é que certos fundamentos morais não são adquiridos pela aprendizagem. Eles não surgem no colo da mãe, nem na escola ou na igreja; ao contrário, são produtos da evolução biológica" (2014, p. 18).

Ao encontro da premissa básica que caracteriza a empatia - compreender o outro para poder no lugar dele se colocar -, Bloom conclui: "Portanto, somos animais sociais desde o início da vida, capazes de fazer uma apreciação básica da mente das outras pessoas" (2014, p. 35). Estando-se dotado de tal capacidade de apreensão daquilo que o semelhante sente, vivencia e pensa, é relevante e factível a hipótese de que se é naturalmente munido de empatia, o que abre caminho para a efetivação de outros atributos éticos.

Por estar alinhado a tal hipótese, destaca-se o trabalho de Cláudia Passos-Ferreira, que chama a atenção ao fato de que, neste início de século XXI, há uma retomada de estudos em psicologia moral que objetivam naturalizar a ética. A autora indaga: “O que significa naturalizar a ética?”. E responde:

A Ética naturalizada busca mostrar que as normas morais emergem e são justificadas por processos puramente naturais e, na gramática atual, por fatos neurobiológicos. Dito de outro modo, o projeto naturalista visa a fundar a ética em categorias universais biológicas, que possam valer para todos os homens em todos os tempos (2011, p. 472).

Passos-Ferreira (2011) confere a reabertura do diálogo acerca da naturalização da ética à descoberta dos neurônios-espelho, feita por Rizzolatti e equipe no ano de 1995:

A equipe italiana descobriu, ao pesquisar como macacos representam e reconhecem a ação motora, a existência de neurônios no córtex pré-motor do macaco que são ativados na presença de uma ação executada ou apenas observada. Verificou-se que esses neurônios respondem a um gesto particular não importando quem está executando o gesto. Se outro macaco, ou até mesmo um humano, está executando uma ação, como por exemplo, estar pegando bananas, os neurônios do córtex pré-motor do macaco que está observando a ação disparam. Esse achado empírico comprova que mesmo em primatas não humanos existem mecanismos de espelhar, apreciar e compreender os alvos que estão sendo intencionados pelos seus coespecíficos (2011, p.472-473).

Tais achados promoveram intensa repercussão em estudos relativos a temas como linguagem, cognição social, psicopatologia, moralidade, empatia - foco do presente estudo -, entre outros aspectos. Há, todavia, controvérsia 
no tocante ao funcionamento dos neurônios-espelho, inclusive no que tange à sua existência. Passos-Ferreira (2011) comenta, em seu texto, estudos que questionam essa teoria. Também Bloom (2014) faz considerações relacionadas a isso, declarando que as primeiras afirmações sobre os neurônios-espelho foram exageradas, visto que os macacos, objetos do estudo inaugural e possuidores desses neurônios, não dominam linguagem nem raciocínio social complexo. $\mathrm{O}$ autor prossegue:

Eles [os neurônios-espelho] são sequer suficientes para explicar a imitação do comportamento dos outros, porque os macacos não imitam outros macacos. Os neurônios-espelho estão localizados em partes do cérebro que são distintas das áreas envolvidas na empatia, e muitos psicólogos e neurocientistas acreditam que, provavelmente, eles não têm nenhuma função social, sendo, antes, especializados no aprendizado de movimentos motores - embora, ainda aqui, haja controvérsias (2014, p. 55).

Esse mesmo autor (2014), entretanto, acredita que os neurônios-espelho são o que há de menos interessante nessa teoria. Em sua visão, o que realmente importa é o fato de que se tem, enquanto ser humano, a aptidão para a empatia, e, segundo ele, tal capacidade deve surgir do cérebro, ainda que por outro mecanismo que não as referidas células.

\section{[ii]}

Quando se aborda a empatia a partir de uma perspectiva biológica ou naturalista, necessariamente é preciso levar em conta a teoria evolucionista de Charles Darwin $(1981 ; 2004)$, visto ser o autor que conseguiu estabelecer uma correlação entre a evolução do ser humano e a dos outros animais. Sendo o ser humano produto da evolução e da adaptação, ele deve compartilhar elementos, capacidades e habilidades naturais com outros animais, especialmente os mais próximos dele na cadeia evolutiva. Nesse sentido, em Darwin, no texto The descent of man, pode-se ler:

A seguinte proposição parece-me altamente provável, a saber, que qualquer animal dotado de instintos sociais bem demarcados inevitavelmente adquirirá senso ou consciência moral, assim que suas capacidades intelectuais se tenham tornado tão bem desenvolvidas, ou quase tão bem desenvolvidas, como no homem (1981, p. 71-72).

Pode-se inferir, a partir desse excerto, que atributos morais como empatia e solidariedade não seriam capacidades exclusivamente humanas, mas compartilhadas na natureza animal. O primatólogo Frans De Waal (2010), em A era da empatia, concorda com Darwin quanto ao seu preceito de que a sociabilidade humana compartilha uma origem 
comum com a sociabilidade animal. Em outros termos, para De Waal $(2006 ; 2007 ; 2010)$, os grandes primatas mamíferos, como chimpanzés e bonobos, compartilham da mesma gênese moral observada em seres humanos, pois em seus comportamentos podem ser solidários e agressivos tanto quanto os homens.

Desse modo, a proposição lançada na consagrada obra darwiniana coloca a moralidade - desenvolvida ao longo do processo evolutivo da espécie humana e composta também pela empatia e pela solidariedade - no patamar das habilidades instintivas e naturais, tanto para os seres humanos quanto para os outros animais sociáveis. Em relação à empatia, De Waal (2010, p. 317) afirma:

[...] dispomos de um instrumento capaz de enriquecer grandemente o nosso modo de pensar e que foi selecionado ao longo de milhões de anos, o que significa que foi testado repetidas vezes em relação ao seu valor de sobrevivência. Trata-se da nossa capacidade de fazer laços com as outras pessoas, de compreendê-las e de nos colocar no lugar delas.

A gênese da empatia está associada à identificação e ao pertencimento a um grupo. De acordo com De Waal (2010), isso ocorre porque para os mamíferos, em decorrência de dependerem necessariamente dos cuidados maternos, os vínculos afetivos têm profundo valor e são fundamentais tanto para a sobrevivência dos indivíduos recém-nascidos como para a manutenção do grupo social. Isto é, “o vínculo é um elemento essencial para a nossa espécie. Não há nada que nos faça mais felizes" (DE WAAL, 2010, p. 29). E vínculos remetem, necessariamente, às relações parentais, como se vê na sequência.

\section{Desenvolvimento da empatia na infância e o papel da família}

Nesta pesquisa, assume-se a perspectiva teórica de que é possível formar ou desenvolver a empatia, a solidariedade e outros elementos da moralidade humana, mesmo que os seres humanos já possuam, desde o nascimento, certas capacidades ou comportamentos pró-sociais. Ou seja, entende-se que a educação possui papel fundamental para a formação das novas gerações intelectual e moralmente. Por educação, compreende-se a formação ampla do ser humano, na forma de um processo de humanização, que ocorre formal e informalmente por meio de processos de aprendizagem no seio da família, no ambiente escolar e na vida social.

A pesquisa que se está realizando apontou que são diversos os fatores implicados no desenvolvimento da empatia. Como exemplo, Justo, Carvalho e Kristensen (2014) afirmam que esses fatores estão divididos em internos (fatores genéticos, aspectos do desenvolvimento neural e variáveis de temperamento) e externos, ou de socialização 
(imitação, estilos parentais e relacionamento pais e filho). Este recorte de pesquisa prioriza o foco sobre os aspectos relacionados à família e à formação.

Para adentrar no terreno das relações familiares, julga-se imprescindível mencionar um fator que influencia o desenvolvimento emocional das crianças desde o nascimento, que é o estabelecimento de apego e vínculo afetivo na relação entre pais e filhos. O modo como agem e reagem os pais, como expressam suas emoções e as condutas dirigidas aos filhos são importantes variáveis implicadas no desenvolvimento da empatia nas crianças (JUSTO, CARVALHO e KRISTENSEN, 2014). Depreende-se que, dependendo de como se dá essa relação e como se criam vínculos entre os genitores e uma criança, resultará em maior ou menor grau de empatia, sem se desconsiderar, obviamente, outros fatores.

Pavarino, Del Prette e Del Prette (2005), em estudo sobre a empatia como mecanismo de prevenção da agressividade na infância, ressaltam que,

[...] embora a empatia seja considerada como produto evolutivo do modo de organização social dos seres humanos e animais, aparecendo desde a mais tenra idade, o seu desenvolvimento depende primariamente das condições de socialização da criança no contexto familiar [...]. Se esse ambiente não for favorável ou a criança experimentar negligência ou abusos, podem ocorrer déficits de empatia que facilitam o comportamento agressivo (p. 129-130).

Garcia (2001, p. 13) reforça a importância parental para as crianças, visto que são os pais os "primeiros modelos significativos de comportamento sócio-afetivo". As relações fraternas também são importantes, porquanto os irmãos constituem o subsistema primário para que ocorra a aprendizagem da interação com colegas. Consoante o referido autor, pode-se afirmar que "normas e valores sociais são transmitidos pelos pais seja através de informação, castigos e punições, bem como de modelagem de comportamentos interpessoais" (GARCIA, 2001, p. 13). A família pode ser entendida, logo, como um microssistema - o primeiro - que permite ao infante realizar a experiência do ato de relacionar-se com os outros. Por isso, depreende-se que a família possui extrema relevância para o desenvolvimento da empatia nas crianças.

No tocante às relações entre adultos e crianças, Bjorklund (1997) afirma que os adultos da espécie, a fim de garantirem o cuidado dos quais as crianças precisam, tiveram de desenvolver suas qualidades concernentes à comunicação e à cooperação. Por outro lado, os bebês são predispostos desde que nascem a captar e a responder a sinais socioemocionais, comportamentos que promovem a vinculação afetiva com os adultos, despertando atenção e cuidados. 
Motta et al. (2006) compreendem que um ambiente que favoreça variadas possibilidades de experimentação e de expressão de emoções dos mais diversos tipos, satisfazendo às necessidades físicas e emocionais da criança, desestimula uma postura autocentrada, de preocupação excessiva consigo mesma. Isso parece facilitar a abertura para a alteridade e para o desenvolvimento de atitudes empáticas.

Para Sampaio, Camino e Roazzi (2009), com o passar do tempo, à medida que aspectos cognitivos e afetivos evoluem, a capacidade empática tende a ser refinada. Relativamente aos benefícios que promove ao desenvolvimento infantil, a empatia pode ser considerada um fator protetivo:

[...] a empatia tem sido considerada um comportamento pró-social. Nessa perspectiva, insere-se nos fatores de proteção, na medida em que neutraliza o impacto do risco, inibindo comportamentos antissociais e favorecendo, assim, um desenvolvimento mais saudável da criança (RODRIGUES e RIBEIRO, 2011, p. 116).

Deduz-se que, devido à forte relevância desse fator, deve a empatia ser promovida durante a infância, nos mais variados contextos, iniciando-se pela família, especialmente por meio das condutas parentais, estendendo-se à família extensa, à escola e à comunidade como um todo. Isso porque não basta o aparelho psíquico da criança ser, ao que tudo indica, equipado naturalmente com a capacidade de colocar-se no lugar do outro e compreender suas sensações; é preciso que o meio externo responda positivamente a tal predisposição, reforçando-a. Nesse sentido, Lyra, Roazzi e Garvey (2008) entendem que o desenvolvimento sociocognitivo infantil consiste em um processo de mútua constituição, composto por um organismo com predisposição a receber e a elaborar informações sociais e por um mundo social que propicia que tais habilidades sociocognitivas se desenvolvam.

\section{Considerações finais}

Com o presente estudo, de natureza qualitativa e no formato de revisão bibliográfica, teve-se o propósito de apresentar resultados parciais encontrados em investigação acerca da gênese da empatia e relativos a como ocorre o seu desenvolvimento na infância, com especial atenção ao papel formativo da família. Os achados, provindos de revisão bibliográfica em livros, artigos científicos e dissertações, após análise hermenêutica, permitiram que se discorresse sobre três importantes aspectos referentes à empatia.

O primeiro aspecto refere-se a uma aproximação histórico-conceitual desse conceito, permitindo contextualizar algumas acepções do termo no decorrer do tempo. Constata-se que a empatia consiste em uma competência antiga, primariamente denominada 'simpatia', e presente em algumas obras de pensadores ocidentais. Também representa 
uma experiência estética do ser humano e é relevante para se entender a capacidade de ação humana em diferentes contextos, bem como para compreender a constituição moral e social da personalidade de cada um.

A gênese da empatia e sua relação com a natureza humana, verificadas em pesquisas que exploram como nasce a competência da empatia e qual a sua relação com aspectos inatos do ser humano, constituem outro ponto deveras relevante no tocante ao conceito em análise. Nesse sentido, encontram-se publicações de duas vertentes: uma relacionada aos estudos com crianças, especificamente com o desenvolvimento ou com a presença da empatia em bebês; e outra compreendendo a empatia, em um contexto naturalista e evolucionista, como uma característica específica dos animais mamíferos.

O terceiro e último aspecto que se destacou entre os achados foi o desenvolvimento da empatia na infância e o papel da família, partindo-se de uma perspectiva teórica de que é possível formar ou desenvolver a empatia, a solidariedade e outros elementos da moralidade humana. As contribuições trazidas nesse sentido revelam que há fatores internos e externos envolvidos no desenvolvimento da empatia. Ademais, o desenvolvimento da empatia depende de condições de socialização da criança no contexto familiar, do modo como agem e reagem os pais, porquanto são os primeiros modelos significativos de comportamento socioafetivo para as crianças. Por fim, ao passo que aspectos cognitivos e afetivos evoluem, a capacidade empática tende a ser refinada, tornando-se um comportamento pró-social, inserindo-se nos fatores de proteção.

Entendem, com base no exposto, que a empatia traduz-se em uma competência fundamental à convivência humana, à manutenção da sociedade e ao cuidado com a vida, sem a qual se torna muito difícil - quiçá impossível manter a civilidade e a organização social. É preciso, portanto, compreendê-la como uma capacidade natural ao ser humano, que necessita ser estimulada e promovida pela via da educação familiar e escolar.

\section{Referências}

ARISTÓTELES. Ética a Nicômaco. 2. ed. Bauru, SP: Edipro, 2007.

BJORKLUND, David F. The role of immaturity in human development. Pychological Bulletin, v. 122, n. 2, p. 153-169, 1997.

BLOOM, Paul. O que nos faz bons ou maus. Rio de Janeiro: BestSeller, 2014.

BUSSAB, Vera Silvia Raad; PEDROSA, Maria Isabel; CARVALHO, Ana Maria Almeida. Encontros com o outro: empatia e intersubjetividade no primeiro ano de vida. Psicologia USP, São Paulo, v. 18, n. 2, p. 99-133, 2007. Disponível em: <http://www. scielo.br/pdf/pusp/v18n2/v18n2a07.pdf>. Acesso em: 20 mar. 2017.

DARWIN, Charles Robert. The descent of man, and selection in relation to sex. Princeton, New Jersey: Princeton University Press, 1981. 
DARWIN, Charles Robert. The origin of species. London: CRW Publishing Limited, 2004.

DE WAAL, Frans. A era da empatia: lições da natureza para uma sociedade mais gentil. São Paulo: Companhia das Letras, 2010.

. Eu, primata: por que somos como somos. São Paulo: Companhia das Letras, 2007.

Primates and philosophers: how morality evolved. Princeton, New Jersey: Princeton University Press, 2006.

DENZIN, Norman K.; LINCOLN, Yvonna S. A disciplina e a prática da pesquisa qualitativa. In: DENZIN, Norman K.; LINCOLN, Yvonna S. (Org.). O planejamento da pesquisa qualitativa: teorias e abordagens. 2. ed. Porto Alegre: Artmed, 2006. p. 15-41.

GADAMER, Hans-Georg. Hermenêutica em retrospectiva: a virada hermenêutica. Petrópolis: Vozes, 2007 , v. 2.

. Verdade e método: traços fundamentais de uma hermenêutica filosófica. 7. ed. Petrópolis: Vozes; Bragança Paulista: São $\overline{\text { Francisco, 2005. Vol. } 1 .}$

GARCIA, Fabíola Alvares. Investigando diferentes indicadores de empatia em meninos e sua relação com a empatia e ações educativas dos pais. 2001. 93 f. Dissertação (Mestrado em Psicologia) - Programa de Pós-Graduação em Psicologia, Departamento de Psicologia e Educação, Universidade de São Paulo, Ribeirão Preto, 2011. Disponível em: <http://betara.ufscar.br:8080/pesquisa/ rihs/pesquisas/armazenagem/pdf/dissertacoes-completas/investigando-diferentes-indicadores-de-empatia-em-meninos-e-sua-relacao-com-aempatia-e-acoes-educativas-dos-pais>. Acesso em: 20 abr. 2017.

GIL, Antonio Carlos. Métodos e técnicas de pesquisa social. 6. ed. São Paulo: Atlas, 2014.

GUTFREIND, Celso. Empatia: do individual ao coletivo. In: VALÉRIO, Marco Antonio Boa Nova (Org.). Umbigo é nosso rei? Considerações sobre o individualismo e o personalismo dos brasileiros. Porto Alegre: Artes e Ofícios, 2006, p. 19-27.

JUSTO, Alice R.; CARVALHO, Janaína C. Núñez; KRISTENSEN, Christian H. Desenvolvimento da empatia em crianças: a influência dos estilos parentais. Psicologia, Saúde \& Doenças, Lisboa, v. 15, n. 2, p. 510-523, 2014. Disponível em: <http://www.scielo.mec.pt/ pdf/psd/v15n2/v15n2a14.pdf>. Acesso em: 10 mar. 2017.

LORDELO, Eulina da Rocha; CARVALHO, Ana Maria Almeida. Comportamento de cuidado entre crianças: uma revisão. Psicologia: Teoria e Pesquisa, Brasília, n. 5, p. 1-19, 1989. Disponível em: <http://periodicos.unb.br/index.php/revistaptp/article/view/20386/14480>. Acesso em: 15 mar. 2017.

LYRA, Pompéia; ROAZZI, Antonio; GARVEY, Andréia. Emergência da teoria da mente em relações sociais. In: SPERB, Tania Mara; MALUF, Maria Regina (Org.). Desenvolvimento sociocognitivo: estudos brasileiros sobre 'teoria da mente'. São Paulo: Vetor, 2008, p. 55-92.

MONTAGNER, Hubert. A criança ator do seu desenvolvimento. Lisboa: Instituto Piaget, 1996.

MOTTA, Danielle da Cunha. Práticas educativas positivas favorecem o desenvolvimento da empatia em crianças. Psicologia em Estudo, Maringá, v. 11, n. 3, p. 523-532, set./dez. 2006. Disponível em: <http://www.scielo.br/pdf/pe/v11n3/v11n3a07>. Acesso em: 11 maio 2017.

PASSOS-FERREIRA, Cláudia. Seria a moralidade determinada pelo cérebro? Neurônios-espelho, empatia e neuromoralidade. Physis Revista de Saúde Coletiva, Rio de Janeiro, v. 21, n. 2, p. 471-490, 2011. Disponível em: <http://www.scielosp.org/scielo.php?script=sci arttext\&pid=S0103-73312011000200008\&lang=pt>. Acesso em: 11 abr. 2017. 
PAVARINO, Michelle Girade; DEL PRETTE, Almir; DEL PRETTE, Zilda A. P. O desenvolvimento da empatia como prevenção da agressividade na infância. Psico, Porto Alegre, PUCRS, v. 36, n. 2, p. 127-134, 2005. Disponível em: <http://revistaseletronicas.pucrs. br/ojs/index.php/revistapsico/article/viewFile/1382/1082>. Acesso em: 2 abr. 2017.

RODRIGUES, Marisa Cosenza; RIBEIRO, Nathalie Nehmy. Avaliação da empatia em crianças participantes e não participantes de um programa de desenvolvimento sociocognitivo. Psicologia: Teoria e Prática, São Paulo, v. 13, n. 2, p. 114-126, 2011. Disponível em: $<$ http://pepsic.bvsalud.org/pdf/ptp/v13n2/v13n2a09.pdf>. Acesso em: 5 maio 2017.

SAMPAIO, Leonardo Rodrigues; CAMINO, Cleonice Pereira dos Santos; ROAZZI, Antonio. Revisão de aspectos conceituais, teóricos e metodológicos da empatia. Psicologia: Ciência e Profissão, Brasília, v. 29, n. 2, p. 212-227, 2009. Disponível em: <http://pepsic. bvsalud.org/pdf/pcp/v29n2/v29n2a02.pdf>. Acesso em: 3 abr. 2017.

SMITH, Adam. Teoria dos sentimentos morais, ou, Ensaio para uma análise dos princípios pelos quais os homens naturalmente julgam a conduta e o caráter, primeiro de seus próximos, depois de si mesmos. 2. ed. São Paulo: WMF Martins Fontes, 2015.

STEIN, Ernildo. Aproximações sobre hermenêutica. Porto Alegre: EdiPUCRS, 1996.

STRATTON, Peter; HAYES, Nicky. Dicionário de Psicologia. São Paulo: Pioneira Thomson Learning, 2003.

STUEBER, Karsten. 'Empathy'. The Stanford Encyclopedia of Philosophy (Fall 2016 Edition). ZALTA, Edward N. (Ed.), 2016. Disponível em: <https://plato.stanford.edu/archives/fall2016/entries/empathy/>. Acesso em: 14 jun. 2017.

STUEBER, Karsten. Rediscovering empathy: agency, folk psychology, and the human sciences. Cambridge, Mass.: MIT Press, 2006. VANDENBOS, Gary R. (Org.). Dicionário de Psicologia da APA. Porto Alegre: Artmed, 2010.

Recebido em: setembro/2017

Aceito em: outubro/2017

Endereço para correspondência:

Av. Vítor Barreto, 2288 - Centro

92010-000 Canoas, RS, Brasil

<gisele.moitoso@gmail.com> 